\title{
Analysis and Implementation of a New Three-Level Converter
}

\author{
Bor-Ren Lin ${ }^{\dagger}$ and Yu-Bin Nian ${ }^{*}$ \\ $\dagger^{* *}$ Department of Electrical Engineering, National Yunlin University of Science and Technology, Yunlin, Taiwan
}

\begin{abstract}
This study presents a new interleaved three-level zero-voltage switching (ZVS) converter for high-voltage and high-current applications. Two circuit cells are operated with interleaved pulse-width modulation in the proposed converter to reduce the current ripple at the input and output sides, as well as to decrease the current rating of output inductors for high-load-current applications. Each circuit cell includes one half-bridge converter and one three-level converter at the primary side. At the secondary side, the transformer windings of two converters are connected in series to reduce the size of the output inductor or switching current in the output capacitor. Based on the three-level circuit topology, the voltage stress of power switches is clamped at $V_{i n} / 2$. Thus, MOSFETs with $500 \mathrm{~V}$ voltage rating can be used at $800 \mathrm{~V}$ input voltage converters. The output capacitance of the power switch and the leakage inductance (or external inductance) are resonant at the transition interval. Therefore, power switches can be turned on under ZVS. Finally, experiments verify the effectiveness of the proposed converter.
\end{abstract}

Key words: DC/DC Converter, PWM

\section{INTRODUCTION}

High-efficiency DC/DC converters have been studied as power units in the mature stage of the telecommunication systems, server systems, data storage systems, medical instruments, and cloud power units. For three-phase power factor correction (PFC) converters, DC bus voltage may be equal to or greater than $500 \mathrm{~V}$ to $800 \mathrm{~V}$. Thus, MOSFETs with 500 or $650 \mathrm{~V}$ voltage stress cannot be used for DC/DC converters at the mature stage. Although high-voltage MOSFETs can be used in DC/DC converters, such as those with $900 \mathrm{~V}$ voltage stress, these units are expensive, and the high turn-on resistance of MOSFETs will reduce circuit efficiency. Three-level or multi-level converters/inverters [1]-[4] have been established by using low-voltage switch devices for high-voltage applications, such as reactive power compensators and high-power motor drives. For modern switching converters, high-efficiency converters are required to reduce circuit size and weight. Therefore, power losses should be reduced to meet this requirement. Soft-switching

Manuscript received Dec. 4, 2013; accepted Mar. 3, 2014

Recommended for publication by Associate Editor Yan Xing.

${ }^{\dagger}$ Corresponding Author: linbr@yuntech.edu.tw

Tel: +886-5-5516128, Fax: +886-5-5312065, National Yunlin

University of Science and Technology

*Department of Electrical Engineering, National Yunlin University of

Science and Technology, Taiwan techniques [5]-[10] with duty cycle control have been developed in three-level converters to reduce the switching losses on power semiconductors. The output capacitance of power switches and the leakage inductance of transformers are resonant at the transition interval to achieve zero voltage switching (ZVS) on power switches. Three-level converters with variable frequency control [11]-[14] have been proposed to enhance circuit efficiency further. If the operating switching frequency is less than the series resonant frequency, the rectifier diodes at the secondary side can be turned off under zero current switching. However, the output ripple current of a three-level resonant converter is larger than that of a conventional three-level PWM converter. Therefore, high output capacitance is necessary for use at the output side.

A new three-level converter is presented for high-inputvoltage applications. The proposed converter includes two circuit cells, which are operated by an interleaved pulse-width modulation (PWM) to reduce the output ripple current and decrease the current stress of passive and active power components. Each circuit cell includes a half-bridge circuit and a three-level PWM circuit. In the proposed three-level converter, the voltage stress of power switches is limited to $V_{i n} / 2$. To reduce the ripple current on the output inductors or capacitor, the transformer secondary windings of two PWM circuits are connected in series at the low-voltage 
side to decrease the output inductor voltage variation. The flying capacitors are used in each circuit cell to balance input split capacitor voltages. Based on the resonant behavior of the output capacitances of MOSFETs and resonant inductance at the transition interval, all power switches can be turned on under ZVS. Finally, experiments based on a laboratory prototype are conducted to verify the effectiveness of the proposed converter.

\section{CIRCUIT CONFIGURATION AND OPERATION PRINCIPLE}

Figs. 1(a) and 1(b) show the circuit configurations of the conventional half-bridge and full-bridge converters with $400 \mathrm{~V}$ input voltage for normal single-phase switching mode power supplies for server power or data storage power units. In Fig. 1(b), the phase-shift PWM scheme is adopted to regulate output voltage and achieve ZVS for all power switches within the desired load range. Normally, the ZVS condition of power switches at the leading leg is easier to be achieved than the power switches at the lagging leg. For three-phase switching mode power converters, the DC bus after the three-phase power factor corrector is normally controlled at $750 \mathrm{~V}$ to $800 \mathrm{~V}$. To use MOSFETs instead of IGBTs for high switching operation, a three-level converter is given in Fig. 1(c). Two clamped diodes and one flying capacitor are adopted to reduce the voltage stress of power switches at $V_{i n} / 2$ and to balance two input capacitor voltages. Two voltage levels, namely, $V_{i n} /(2 n)$ and 0 , are observed at the rectified voltage $v_{\text {rect }}$. If the voltage variation across the output inductor is decreased, the current ripple on the output inductor can be decreased. Thus, one more half-bridge converter can be added to the conventional three-level DC converter to reduce the current ripple at output side. Fig. 2(a) shows the circuit configuration of the proposed three-level converter. The proposed converter includes a conventional three-level converter [Fig. 1(c)] and a half-bridge converter [Fig. 1(a)] to reduce the voltage variation on the output inductor. The input voltage $V_{\text {in }}$ is obtained from a three-phase AC/DC converter with PFC. $C_{1}$ and $C_{2}$ are input as split capacitances to obtain the equal voltages $V_{C I}=V_{C 2}=V_{i n} / 2$. $S_{1}-S_{4}$ are power MOSFETs with $V_{i n} / 2$ voltage stress. The average voltages of flying capacitors are $V_{C f 1}=V_{C f 2}=V_{i n} / 4$. $C_{r I}-C_{r 4}$ are the output capacitances of $S_{I}-S_{4}$, respectively. $L_{r I}$ and $L_{r 2}$ are resonant inductances. $L_{o}$ is the output inductance. $D_{1}$ and $D_{2}$ are rectifier diodes. $T_{1}$ and $T_{2}$ are the isolated transformers. $C_{o}$ and $R_{o}$ denote output capacitance and load resistance, respectively. In the proposed circuit, a three-level converter and a half-bridge converter are used to achieve ZVS turn-on for all switches and to reduce the output inductance or output capacitance. Components $C_{f l}, C_{f 2}, S_{3}, S_{4}$, $T_{2}$, and $L_{r 2}$ are operated as an uncontrolled half-bridge converter with $50 \%$ duty cycle. Two voltage levels, $V_{i n} / 4$ and

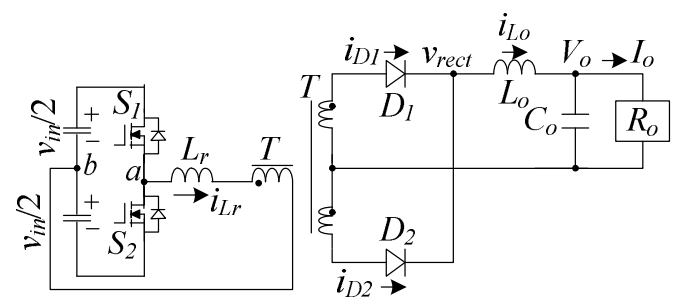

(a)

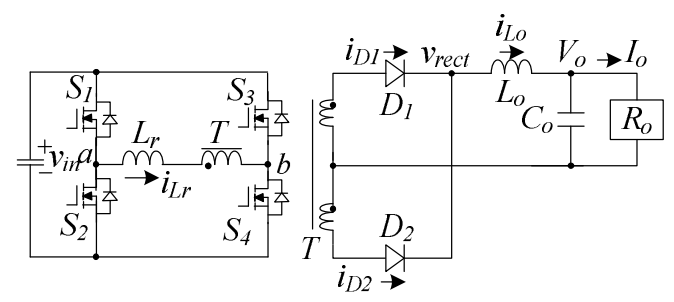

(b)

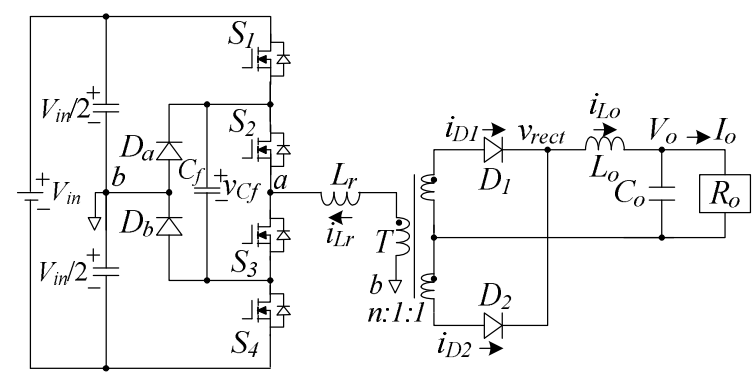

(c)

Fig. 1. Circuit configurations. (a) Conventional PWM half-bridge converter. (b) Conventional phase-shift full-bridge converter. (c) Conventional three-level converter.

$-V_{i n} / 4$, are generated on $v_{a c}$. Components $C_{1}, C_{2}, D_{a}, D_{b}, C_{f l}$, $C_{f 2}, S_{l}-S_{4}, L_{r l}$, and $T_{1}$ are operated as the conventional three-level converter. Three voltage levels, namely, $V_{i n} / 2,0$, and $-V_{i n} / 2$, are generated on $v_{a b}$. Two voltage levels, $V_{i n} /\left(2 n_{1}\right)+V_{i n} /\left(4 n_{2}\right)$ and $V_{i n} /\left(4 n_{2}\right)$, can be observed on the rectified voltage $v_{\text {rect }}$. Thus, low ripple current or switching current on the output inductor can be achieved because of the low voltage across the output inductor. The output capacitances of $S_{1}-S_{4}$ and the resonant inductance (or transformer leakage inductance) are resonant at the transition interval. Therefore, $S_{I}-S_{4}$ can be turned on under ZVS. To reduce the current ripple further at the input and output sides, as well as to reduce the current rating of output inductor for high load current application, an interleaved three-level converter is shown in Fig. 2(b). The interleaved PWM scheme is adopted to generate eight gate signals of $S_{I}-S_{4}$. The input and output ripple currents of two converters can partially cancel each other. Therefore, the input and output capacitances and output inductances can be reduced.

The system analysis of the proposed converter is based on the following assumptions: (1) $V_{C f 1}=V_{C f 2}=V_{C f 3}=V_{C f 4}=V_{i n} / 4$; (2) $V_{C l}=V_{C 2}=V_{C 3}=V_{C 4}=V_{i n} / 2$; (3) $C_{r 1}=C_{r 2}=\ldots=C_{r 7}=C_{r 8}=C_{r}$; (4) $S_{I}-S_{8}, D_{1}-D_{4}$, and $D_{a}-D_{d}$ are ideal; (5) turn ratio of $T_{1}$ and $T_{3}$ 


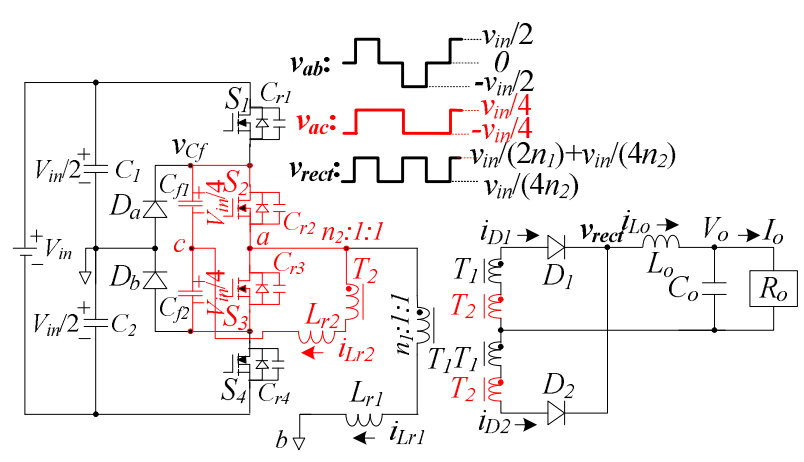

(a)

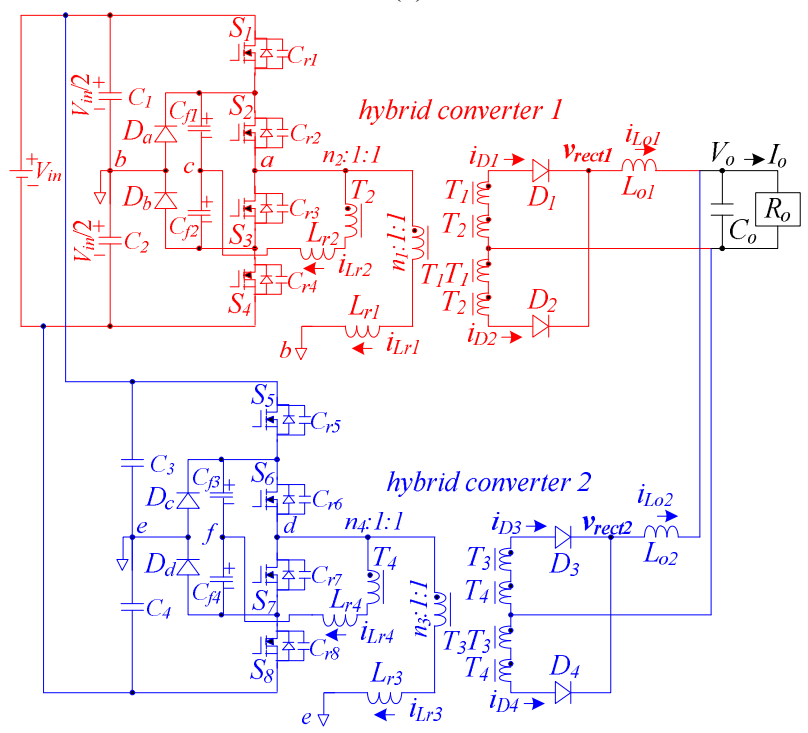

(b)

Fig. 2. Circuit configuration. (a) New three-level converter. (b) Adopted interleaved three-level converter.

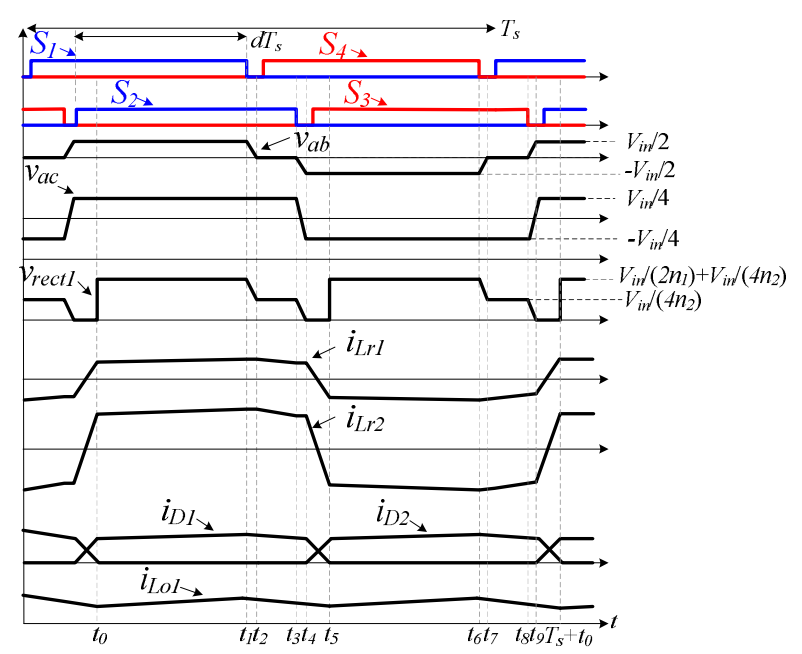

Fig. 3. Main waveforms of three-level converter 1.

is $n_{1}=n_{3}=n$ and that of $T_{2}$ and $T_{4}$ is $n_{2}=n_{4}=n / 2$; and (6) the energy stored in the resonant inductances is greater than that stored in the resonant capacitances, such that the ZVS turn-on of all switches can be achieved. Based on the on/off states of
$S_{I}-S_{8}, D_{a}-D_{d}$, and $D_{I}-D_{4}, 10$ operation modes exist in each three-level converter during one switching cycle. The key waveforms of each three-level converter during one switching cycle are given in Fig. 3. Fig. 4 shows the key waveforms of the proposed interleaved three-level converter. Two output inductor currents partially cancelled each other. Two three-level converters have the same operation modes. Thus, only the operation modes of converter 1 are discussed to simplify the system analysis. Three-level converter 1 has 10 operation modes (Fig. 5). Prior to $t_{0}, S_{1}, S_{2} D_{l}$, and $D_{2}$ are conducting. Inductor currents $i_{L r 1}$ and $i_{L r 2}$ are increasing.

Mode $1 / t_{0} \leq t<t_{1}$, Fig. 5(a)l: At $t_{0}, i_{D 2}$ is decreased to zero current, such that $D_{2}$ is off. $S_{I}$ and $S_{2}$ are still turned on, such that $v_{a b}=V_{i n} / 2, v_{a c}=v_{C f l}=V_{i n} / 4, v_{\text {rect } 1} \approx V_{i n} /\left(2 n_{1}\right)+V_{i n} /\left(4 n_{2}\right)=V_{i n} / n$, and $v_{L o I}=V_{i n} / n-V_{o}>0$. The output inductor current $i_{L o I}$ and the primary currents $i_{L r 1}$ and $i_{L r 2}$ increase in this mode. Power is transferred from input voltage source $V_{\text {in }} / 2$ to output load $R_{o}$.

Mode 2 [t $t_{1} \leq t<t_{2}$ Fig. 5(b)]: At $t_{l}, S_{l}$ is turned off. Given that $i_{L r 1}>0$ and $i_{L r 2}>0, C_{r I}$ and $C_{r 4}$ are charged and discharged in this mode. If the energy stored in $L_{r I}$ and $L_{o I}$ is greater than the energy stored in $C_{r l}$ and $C_{r 4}$, then $C_{r 4}$ can be discharged to zero voltage. The ZVS turn-on condition of $S_{4}$ can be expressed as

$$
\left(L_{r 1}+n^{2} L_{o 1}\right) i_{L r 1}^{2}\left(t_{1}\right) \geq C_{r} V_{i n}^{2} / 2
$$

This mode ends at $t_{2}$ when $v_{C r I}=V_{i n} / 2$ and $v_{C r 4}=0$.

Mode 3 [t $\underline{t}_{2} \leq \boldsymbol{t}<\boldsymbol{t}_{3}$, Fig. 5(c)l: At $t_{2}, v_{C r l}=V_{i n} / 2, v_{C r 4}=0$, and $D_{a}$ are conducting. Capacitor voltage $v_{C 2}=v_{C f 1}+v_{C f 2}=V_{i n} / 2$. Given that $i_{L r 1}>0$, the anti-parallel diode of $S_{4}$ is conducting. Thus, $S_{4}$ can be turned on at this moment to achieve ZVS. In this mode, the primary side voltage $v_{a b}=0$ and $v_{a c}=v_{C f I}=V_{i n} / 4$, and the secondary side voltage $v_{\text {rectl }}=V_{\text {in }} /(2 n)$. The output inductor voltage $v_{L o l}=V_{i n} /(2 n)-V_{o}<0$, such that that the output inductor current $i_{L o l}$ decreases in this mode.

Mode 4 [ $\mathbf{t}_{3} \leq \boldsymbol{t}<\boldsymbol{t}_{4}$, Fig. 5(d)]: At $t_{3}, S_{2}$ is turned off. Given that $i_{L r 1}>0$ and $i_{L r 2}>0, C_{r 2}$, and $C_{r 3}$ are charged and discharged, respectively. If the energy stored in $L_{r 1}, L_{r 2}$, and $L_{o l}$ is greater than the energy stored in $C_{r 2}$ and $C_{r 3}$, then $C_{r 3}$ can be discharged to zero voltage. Thus, the ZVS turn-on condition of $S_{3}$ can be obtained in (2).

$$
\left(L_{r 1}+n^{2} L_{o 1}\right) i_{L r 1}^{2}\left(t_{3}\right)+\left(L_{r 2}+n^{2} L_{o 1} / 4\right) i_{L r 2}^{2}\left(t_{3}\right) \geq C_{r} V_{i n}^{2} / 2(2)
$$

Mode 5 [t $t_{4} \leqq t<t_{5}$, Fig. 5(e)]: At time $t_{4}, v_{C r 2}=V_{i n} / 2$, and $v_{C r 3}=0$. Given that $i_{L r 1}>0$ and $i_{L r 2}>0$, the anti-parallel diode of $S_{3}$ is conducting. $S_{3}$ can be turned on at this moment under ZVS. $D_{1}$ and $D_{2}$ are conducting to commutate the inductor current $i_{\text {Lol }}$. The secondary side voltage $v_{\text {rect }}=0$, and the inductor current $i_{L o l}$ is decreasing. The primary inductor currents $i_{L r 1}$ and $i_{L r 2}$ decrease with the slopes $-V_{i n} /\left(2 L_{r 1}\right)$ and $-V_{i n} /\left(4 L_{r 2}\right)$, 


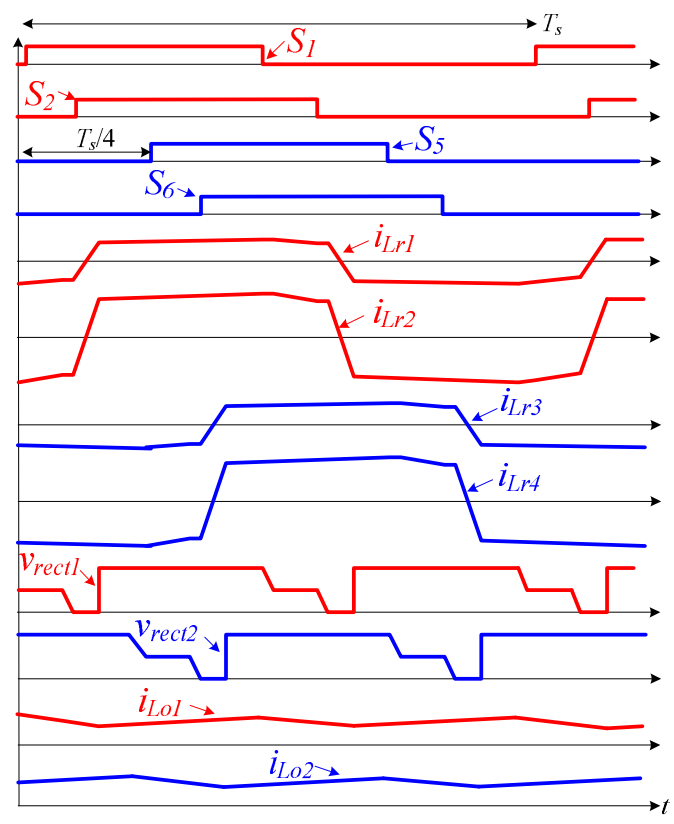

Fig. 4. Key waveforms of the proposed interleaved three-level converter.

respectively. The slopes of the diode currents $i_{D 1}$ and $i_{D 2}$ are given by

$$
\frac{d i_{D 1}(t)}{d t}=-\frac{n V_{i n}}{4 L_{r 1}}=-\frac{n V_{i n}}{16 L_{r 2}}, \frac{d i_{D 2}(t)}{d t}=\frac{n V_{i n}}{4 L_{r 1}}=\frac{n V_{i n}}{16 L_{r 2}}
$$

Based on (3), the relationship of $L_{r 1}$ and $L_{r 2}$ can be described as $L_{r I}=4 L_{r 2}$. At $t_{5}, i_{D 1}$ is decreased to zero current. The current variation on inductor $L_{r l}$ is $\Delta i_{L r 1}=i_{L r 1}\left(t_{5}\right)-i_{L r 1}\left(t_{4}\right) \approx-I_{o} /(2 n)-I_{o} /(2 n)=-I_{o} / n \quad$. The time interval in this mode is given as

$$
\Delta t_{45}=t_{5}-t_{4}=-\frac{I_{o}}{n} \times\left(-\frac{2 L_{r 1}}{V_{\text {in }}}\right)=\frac{2 I_{o} L_{r 1}}{n V_{\text {in }}}
$$

In this mode, $S_{3}, S_{4}, D_{1}$, and $D_{2}$ are conducting, and the rectified voltage $v_{\text {rectl }}=0$. No power is transferred from input voltage source $V_{\text {in }}$ to output load $R_{o}$. The duty loss in this mode can be expressed as

$$
d_{\text {loss }, 5}=\frac{\Delta t_{45}}{T_{s}} \approx \frac{2 I_{o} L_{r 1} f_{s}}{n V_{\text {in }}}
$$

Mode $6 \quad\left[t_{5} \leq t_{1}<t_{6}\right.$. Fig. 5(f)l: At $t_{5}, i_{D I}=0 . S_{3}$ and $S_{4}$ are conducting. The primary side $\mathrm{AC}$ voltages $v_{a b}=-V_{i n} / 2$ and $v_{a c}=-v_{C f 2}=-V_{i n} / 4$, and the output inductor voltage $v_{L o l}=V_{i n} / n-V_{o}>0$. The primary side inductor currents $i_{L r l}$ and $i_{L 2}$ both decrease, whereas the output inductor current $i_{L o l}$ increases in this mode.

Mode 7 [t $t_{6} \leq t<t_{7}$ Fig. 5(g)l: At $t_{6}, S_{4}$ is turned off. Given that $i_{L r 1}<0$ and $i_{L r 2}<0, C_{r 1}$ and $C_{r 4}$ are discharged and charged, respectively. The ZVS turn-on condition of $S_{l}$ can be expressed as

$$
\left(L_{r 1}+n^{2} L_{o 1}\right) i_{L r 1}^{2}\left(t_{6}\right) \geq C_{r} V_{i n}^{2} / 2
$$

At $t_{7}, C_{r l}$ is discharged to zero voltage.

Mode $8\left\lceil\underline{t}_{7} \underline{\underline{t}} \leq \underline{t}_{\underline{8}}\right.$, Fig. 5(h)l: At $t_{7}, v_{C r l}=0$, and $v_{C r 4}=V_{i n} / 2$. Given that $i_{L r I}<0$, the anti-parallel diode of $S_{l}$ is conducting. $S_{l}$ can be turned on at this moment under ZVS. $D_{b}$ is conducting, and the AC terminal voltages $v_{a b}=0$ and $v_{a c}=-v_{C f 2}=-V_{i n} / 4$. The primary inductor currents $i_{L r 1}$ and $i_{L r 2}$ are both decreasing. The rectified voltage $v_{\text {rectl }}=V_{\text {in }} /(2 n)$, and the output inductor voltage $v_{L o l}=V_{i n} /(2 n)-V_{o}<0$, such that $i_{L o l}$ decreases in this mode.

Mode 9 [t $t_{8} \leq t<t_{2}$, Fig. 5(i)]: At $t_{8}, S_{3}$ is turned off. Given that $i_{L r 1}<0$ and $i_{L r 2}<0, C_{r 2}$ and $C_{r 3}$ are discharged and charged, respectively. Similar to (2), the ZVS turn-on condition of $S_{2}$ can be obtained as

$$
\left(L_{r 1}+n^{2} L_{o 1}\right) i_{L r 1}^{2}\left(t_{8}\right)+\left(L_{r 2}+n^{2} L_{o 1} / 4\right) i_{L r 2}^{2}\left(t_{8}\right) \geq C_{r} V_{i n}^{2} / 2
$$

Mode $10\left[\boldsymbol{t}_{9} \leq \boldsymbol{t}<\boldsymbol{t}_{0}+\underline{T}_{2}\right.$ Fig. 5(j)]: At $t_{9}, C_{r 2}$ is discharged to zero voltage. Given that $i_{L r I}\left(t_{9}\right)+i_{L r 2}\left(t_{9}\right)<0$, the anti-parallel diode of $S_{2}$ is conducting. $S_{2}$ can be turned on at this moment under ZVS. $D_{1}$ and $D_{2}$ are conducting to commutate the load inductor current $i_{L o l}$. In this mode, $S_{1}, S_{2}, D_{1}$, and $D_{2}$ are conducting. Thus, the rectified voltage $v_{\text {rectl }}=0$ and the inductor voltage $v_{L o l}=-V_{o}$. No power is transferred from input voltage source $V_{i n}$ to output load $R_{o}$. Thus, the duty loss in this mode is given as

$$
d_{\text {loss }, 10}=\frac{\Delta t_{09}}{T_{s}} \approx \frac{2 I_{o} L_{r 1} f_{s}}{n V_{\text {in }}}=d_{\text {loss }, 5}
$$

At $t_{0}+T_{s}, i_{D 2}$ is decreased to zero current. The circuit operations of the proposed converter in a switching period are then completed.

\section{CIRCUIT CHARACTERISTICS}

In the above discussions, the charge and discharge times of $C_{r l}-C_{r 4}$ in modes $2,4,7$, and 9 are significantly less than the other time intervals. Thus, these modes can be neglected in the discussion of circuit characteristics. From modes 3 and 8 in Fig. 5, the spite capacitor voltages $v_{C l}-v_{C 4}$ can be obtained as $v_{C l}=v_{C 2}=v_{C 3}=v_{C 4}=V_{i n} / 2$. Applying the volt-second balance to $L_{r 2}$ and $T_{2}$ in steady state, the average capacitor voltages $V_{C f I}-V_{C f 4}$ can be derived as

$$
V_{C f 1}=V_{C f 2}=V_{C f 3}=V_{C f 4}=V_{i n} / 4
$$

Based on the volt-second balance on output inductors $L_{o l}$ and $L_{o 2}$, the output voltage $V_{o}$ can be derived as

$$
\begin{aligned}
V_{o} & =\frac{V_{\text {in }}}{n}\left(0.5+d-2 d_{\text {loss }, 10}\right)-V_{f} \\
& =\frac{V_{\text {in }}}{n}\left(0.5+d-\frac{4 L_{r 1} I_{o} f_{s}}{n V_{\text {in }}}\right)-V_{f}
\end{aligned}
$$

where $V_{f}$ is the voltage drop on diodes $D_{I}-D_{4}$; and $d$ is the duty ratio of the AC side voltages $v_{a b}, v_{a c}, v_{d e}$, and $v_{d f}$. The ripple currents of $L_{o l}$ and $L_{o 2}$ are expressed in (11). 


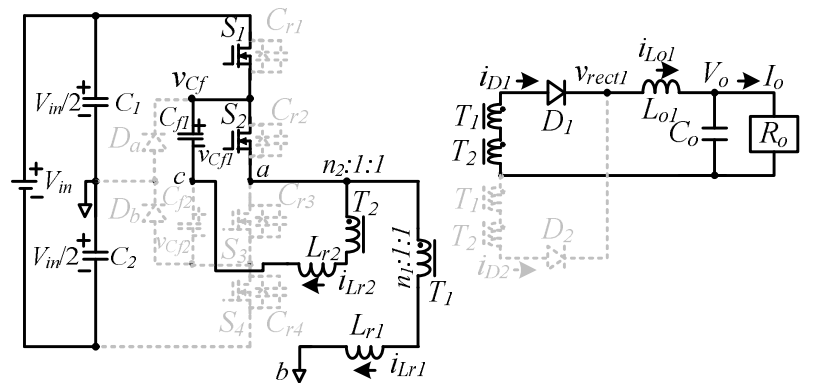

(a)

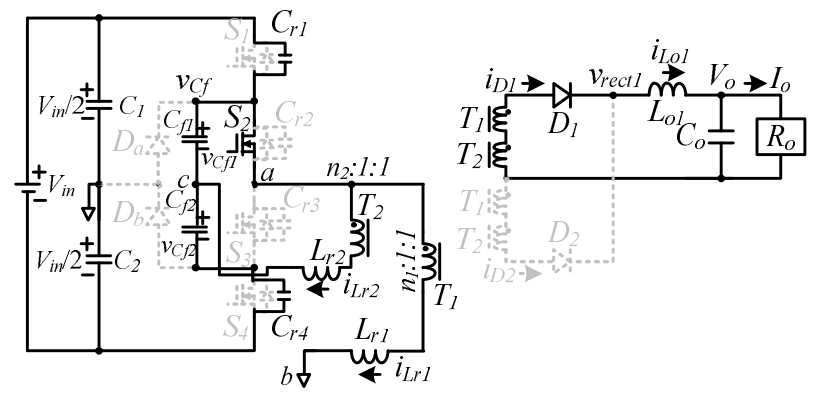

(b)

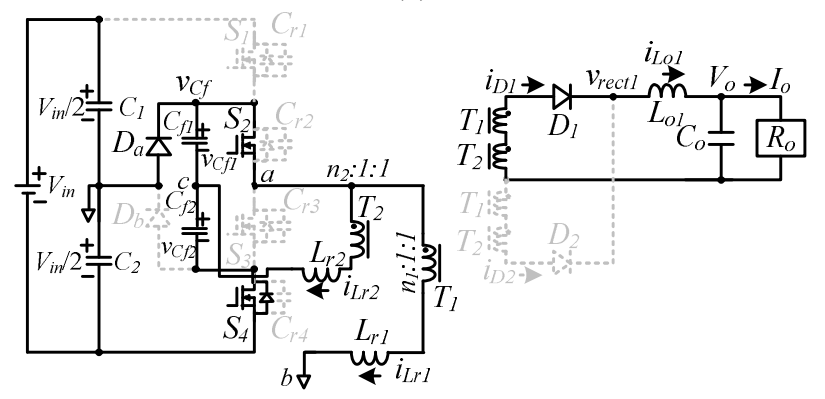

(c)

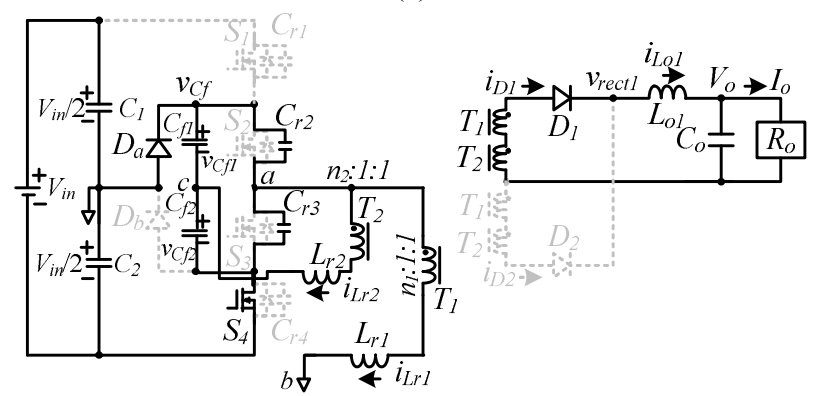

(d)

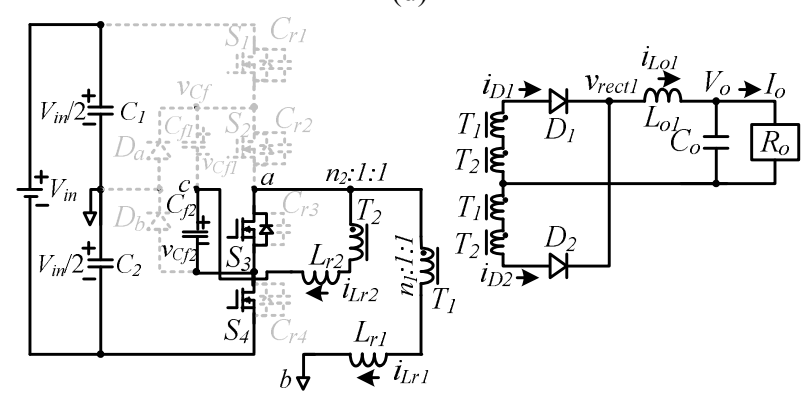

(e)

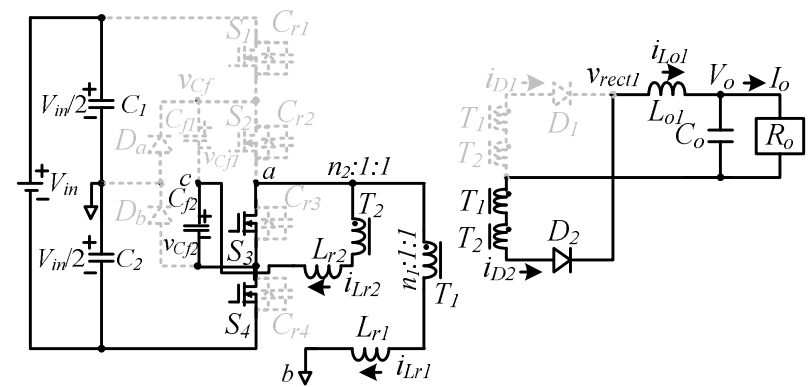

(f)

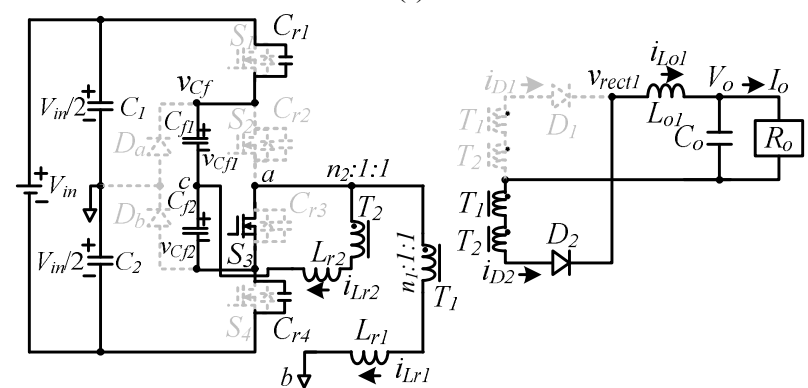

(g)

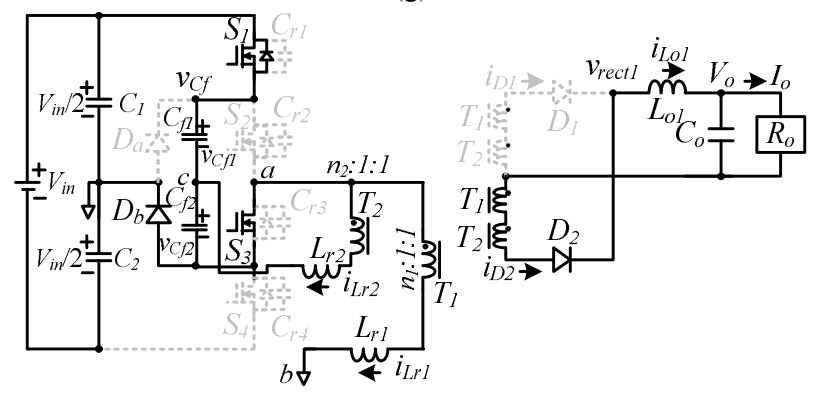

(h)

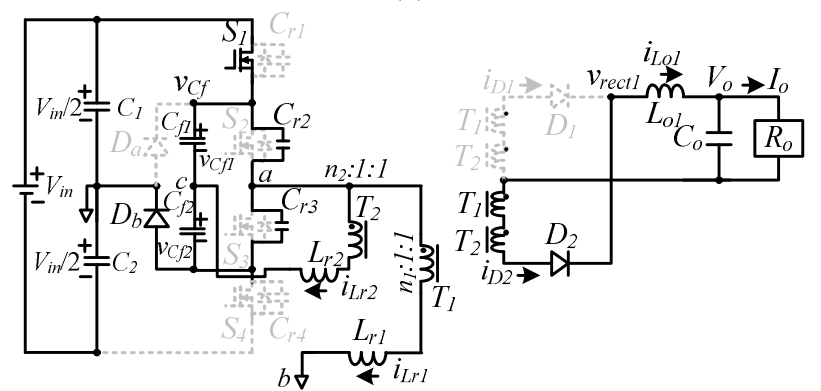

(i)

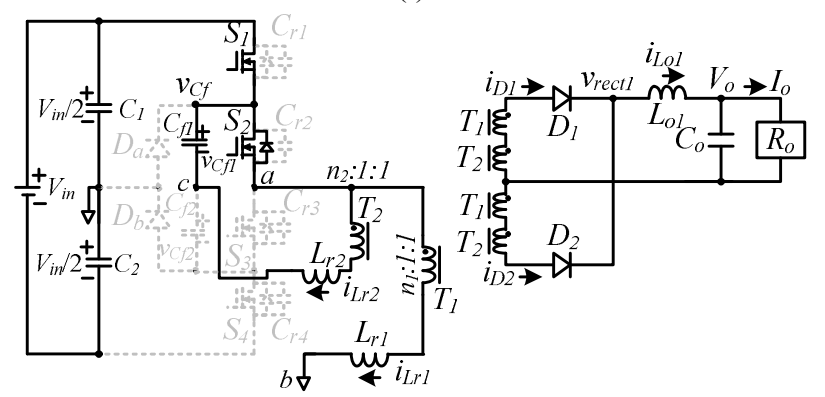

(j)

Fig. 5. Operation modes of the proposed converter during one switching cycle. (a) Mode 1. (b) Mode 2. (c) Mode 3. (d) Mode 4. (e) Mode 5. (f) Mode 6. (g) Mode 7. (h) Mode 8. (i) Mode 9. (j) Mode 10. 
$\Delta i_{L o 1}=\Delta i_{L o 2}=\frac{\left(V_{i n} / n-V_{o}-V_{f}\right)}{L_{o} f_{s}}\left(d-\frac{2 I_{o} L_{r 1} f_{s}}{n V_{\text {in }}}\right)=r I_{o} / 2$

where $r$ is the current ripple factor of output inductors. The maximum output inductor currents at steady state are expressed in (12).

$$
\begin{aligned}
i_{L o 1, \max } & =i_{L o 2, \max }=(1+0.5 r) I_{o} / 2 \\
& =\frac{I_{o}}{2}+\frac{\left(V_{i n} / n-V_{o}-V_{f}\right)}{2 L_{o} f_{s}}\left(d-\frac{2 I_{o} L_{r 1} f_{s}}{n V_{i n}}\right)
\end{aligned}
$$

In modes 1 and 6 , the magnetizing ripple currents $\Delta i_{L m I}-\Delta i_{L m 4}$ can be expressed in (13) and (14).

$$
\begin{aligned}
& \Delta i_{L m 1}=\Delta i_{L m 3} \approx \frac{V_{\text {in }}\left(d-d_{\text {loss }, 10}\right) T_{s}}{2 L_{m 1}}=\frac{d V_{i n} T_{s}}{2 L_{m 1}}-\frac{I_{o} L_{r 1}}{n L_{m 1}} \\
& \Delta i_{L m 2}=\Delta i_{L m 4} \approx \frac{V_{i n}\left(d-d_{\text {loss }, 5}\right) T_{s}}{4 L_{m 2}}=\frac{d V_{i n} T_{s}}{4 L_{m 2}}-\frac{I_{o} L_{r 1}}{2 n L_{m 2}}
\end{aligned}
$$

where $L_{m l}=L_{m 3}$, and $L_{m 2}=L_{m 4}$. The average diode currents $i_{D 1, a v}-i_{D 4, a v}$ and the diode voltage stresses $v_{D 1, \text { stress }}-v_{D 4, \text { stress }}$ are given in (15) and (16), respectively.

$$
\begin{aligned}
i_{D 1, \mathrm{av}} & =i_{D 2, a v}=i_{D 3, \mathrm{av}}=i_{D 4, a v} \approx I_{o} / 4 \\
v_{D 1 \text {,stress }} & =v_{D 2 \text {,stress }}=v_{D 3 \text {, stress }}=v_{D 4 \text {,stress }} \approx 2 V_{\text {in }} / n
\end{aligned}
$$

If the ripple currents of $S_{1}-S_{8}$ can be ignored, the root-mean-square $(\mathrm{rms})$ currents and the voltage stress of $S_{1}-S_{8}$ are given in (17)-(19).

$$
\begin{aligned}
& i_{S 1, r m s}=i_{S 4, r m s}=i_{S 5, r m s}=i_{S 8, r m s} \approx \frac{I_{o}}{2 n \sqrt{2}} \\
& i_{S 2, r m s}=i_{S 3, r m s}=i_{S 6, r m s}=i_{S 7, r m s} \approx \frac{3 I_{o}}{2 n \sqrt{2}} \\
& v_{S 1, \text { stress }}=\ldots=v_{S 8, \text { stress }} \approx V_{\text {in }} / 2
\end{aligned}
$$

In mode $2, i_{L r I}\left(t_{l}\right)$ can be expressed as

$$
\begin{aligned}
& i_{L r 1}\left(t_{1}\right)=-i_{L r 1}\left(t_{6}\right) \approx i_{L m 1, \max }+\frac{i_{L o 1, \max }}{n} \\
& =\frac{d V_{i n} T_{s}}{4 L_{m 1}}-\frac{I_{o} L_{r 1}}{2 n L_{m 1}}+\frac{I_{o}}{2 n}+\frac{\left(V_{i n} / n-V_{o}-V_{f}\right)}{2 n L_{o} f_{s}}\left(d-\frac{2 I_{o} L_{r 1} f_{s}}{n V_{i n}}\right)
\end{aligned}
$$

In mode 4 , the inductor currents $i_{L r 1}\left(t_{3}\right)$ and $i_{L r 2}\left(t_{3}\right)$ can be expressed as

$$
\begin{aligned}
& i_{L r 1}\left(t_{3}\right)=-i_{L r 1}\left(t_{8}\right) \approx i_{L r 1}\left(t_{1}\right)-\frac{\left(V_{o}+V_{f}-V_{i n} / 2 n\right) \Delta t_{23}}{n L_{o}} \\
& =\frac{d V_{i n} T_{s}}{4 L_{m 1}}-\frac{L_{r 1} I_{o}}{2 n L_{m 1}}+\frac{I_{o}}{2 n}+\frac{\left(V_{i n} / n-V_{o}-V_{f}\right)}{2 n L_{o} f_{s}}\left(d-\frac{2 L_{r 1} I_{o} f_{s}}{n V_{i n}}\right)(21) \\
& -\frac{\left(V_{o}+V_{f}-V_{i n} / 2 n\right)(0.5-d)}{n L_{o} f_{s}} \\
& i_{L r 2}\left(t_{3}\right)=i_{L r 2}\left(t_{8}\right) \approx i_{L m 2, \max }+\frac{i_{L o 1}\left(t_{3}\right)}{n / 2} \\
& =\frac{d V_{i n} T_{s}}{8 L_{m b}}-\frac{L_{r 1} I_{o}}{4 n L_{m 2}}+\frac{I_{o}}{n}+\frac{\left(V_{i n} / n-V_{o}-V_{f}\right)}{n L_{o} f_{s}}\left(d-\frac{2 L_{r 1} I_{o} f_{s}}{n V_{i n}}\right) \\
& -\frac{2\left(V_{o}+V_{f}-V_{i n} / 2 n\right)(0.5-d)}{n L_{o} f_{s}}
\end{aligned}
$$

Based on (1), (6), and (20), the necessary resonant inductance
$L_{r l}$ for ZVS turn-on of $S_{I}$ and $S_{4}$ is expressed in (23).

$$
L_{r 1} \geq \frac{C_{r} V_{i n}^{2}}{2 i_{L r 1}^{2}\left(t_{1}\right)}-n^{2} L_{o 1}
$$

From (2), (7), (21), and (22), the necessary resonant inductance $L_{r 2}$ for ZVS turn-on of $S_{2}$ and $S_{3}$ is given in (24).

$$
L_{r 2} \geq\left[\frac{C_{r} V_{i n}^{2}}{2}-\left(L_{r 1}+n^{2} L_{o 1}\right) i_{L r 1}^{2}\left(t_{3}\right)\right] / i_{L r 2}^{2}\left(t_{3}\right)-n^{2} L_{o 1}
$$

Given that the switch currents $i_{S 5}-i_{S 8}$ are similar to $i_{S 1}-i_{S 4}$ in steady state, the necessary resonant inductances $L_{r 3}$ and $L_{r 4}$ are equal to $L_{r 1}$ and $L_{r 2}$, respectively, to achieve ZVS conditions of $S_{5}-S_{8}$.

\section{EXPERIMENTAL RESULTS}

A laboratory prototype shown in Fig. 6 is implemented to verify the effectiveness of the proposed converter. The electrical specifications of the proposed converter are $V_{i n}=750$ $\mathrm{V}-800 \mathrm{~V}, V_{o}=48 \mathrm{~V}, I_{o}=40 \mathrm{~A}$, and $f_{s}=100 \mathrm{kHz}$. The resonant inductances in this prototype are $L_{r l}=L_{r 3}=48 \mu \mathrm{H}$ and $L_{r 2}=L_{r 4}=12 \mu \mathrm{H}$. The magnetic core TDK EER-40C is used for $T_{1}-T_{4}$. The winding turns of $T_{1}$ and $T_{3}$ a 48:4:4 and the winding turns of $T_{2}$ is 30:5:5. The magnetizing inductances $L_{m 1}=L_{m 3}=2.3 \mathrm{mH}$ and $L_{m 2}=L_{m 4}=1.2 \mathrm{mH}$, and the output inductances $L_{o I}=L_{o 2}=1 \quad 2 \mu H$. MOSFETs IRFP460 with $V_{D S}=500 \mathrm{~V}, I_{d, r m s}=20 \mathrm{~A}$ are used for switches $S_{I}-S_{8}$. The KCU30A30 fast recovery diodes with $300 \mathrm{~V}$ voltage rating and $30 \mathrm{~A}$ average current are used for $D_{I}-D_{4}$. Fast recovery diodes 30ETH06 are adopted for the clamped diodes $D_{a}-D_{d}$. The DC input capacitances $C_{l}-C_{4}$ are $220 \mu \mathrm{F}$. The flying capacitances $C_{f l}-C_{f 4}$ are $1 \mu \mathrm{F}$. The output capacitance $C_{o}$ is $4000 \mu \mathrm{F}$. The measured waveforms of the PWM signals of $S_{I}-S_{4}$ of the first circuit cell at full load are shown in Fig. 7. Fig. 8 provides the measured gate voltages of $S_{1}$ and $S_{2}$ in the first circuit cell and those of $S_{5}$ and $S_{6}$ in the second circuit cell under full load conditions. $S_{5}$ and $S_{6}$ in the second circuit are clearly phase-shifted by one-fourth of the switching period with respect to $S_{I}$ and $S_{2}$ in the first circuit. Fig. 9 shows the measured results of the AC side voltages $v_{a b}-v_{d f}$ and the rectified voltages $v_{\text {rectl }}$ and $v_{\text {rect } 2}$ at full load. Three voltage levels, $V_{\text {in }} / 2,0$, and $-V_{i n} / 2$, are generated on AC side voltages $v_{a b}$ and $v_{d e}$; and two voltage levels $V_{i n} / 4$ and $-V_{i n} / 4$ are generated on voltages $v_{a c}$ and $v_{d f}$. Three voltage levels, $V_{i n} / n, V_{i n} /(2 n)$, and 0 , are shown at the rectified voltages $v_{\text {rect } 1}$ and $v_{\text {rect } 2}$. Fig. 10 gives the measured results of gate voltage, drain voltage, and switch current of $S_{I}$ at half and full load conditions under $800 \mathrm{~V}$ input voltage. Similarly, the measured gate voltage, drain voltage, and switch current of $S_{2}$ at $50 \%$ and $100 \%$ loads are given in Fig. 11. Figs. 10 and 11 clearly show that $S_{1}$ and $S_{2}$ are all turned on under ZVS. $S_{3}$ and $S_{4}$ have the same switch current and voltage waveforms as $S_{2}$ and $S_{1}$, respectively. Thus, $S_{3}$ and $S_{4}$ are also turned on 


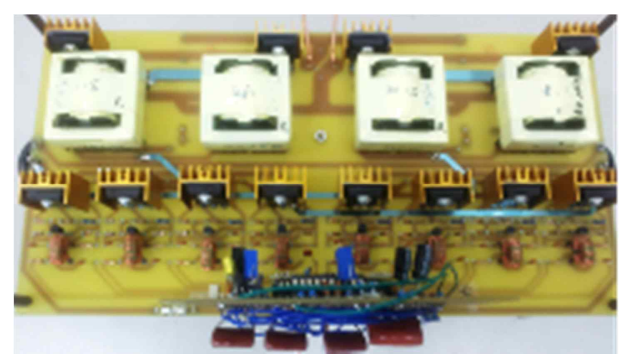

Fig. 6. Photograph of the prototype circuit.

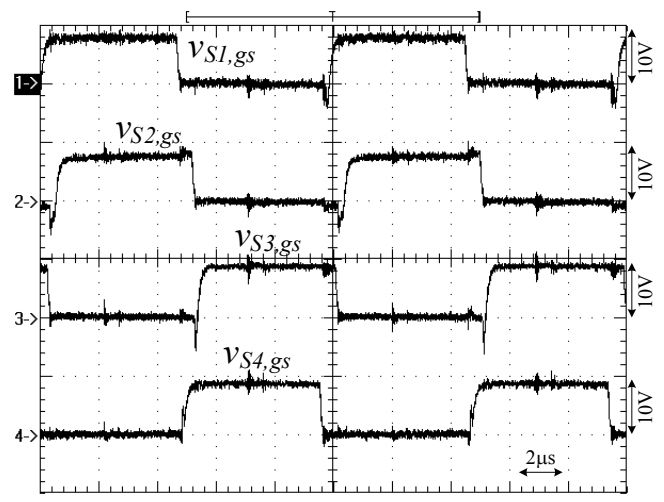

Fig. 7. Measured results of gate voltages of $S_{I}-S_{4}$ at full load.

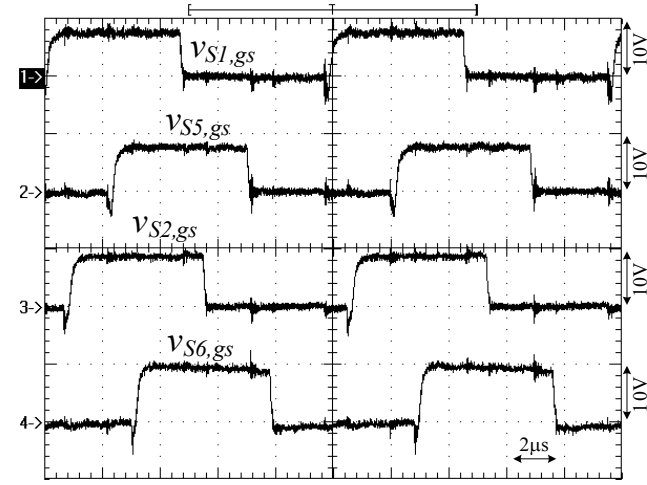

Fig. 8. Measured results of gate voltages of $S_{1}, S_{2}, S_{5}$, and $S_{6}$ at full load.

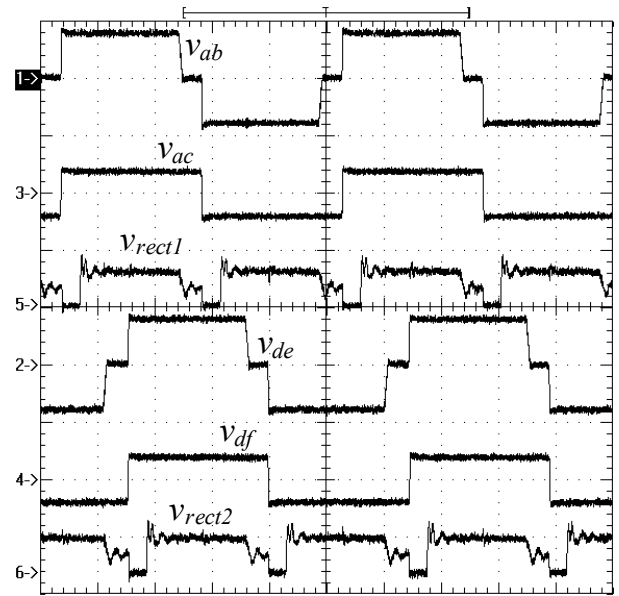

Fig. 9. Measured results of the AC side voltages $v_{a b}-v_{d f}$ and the rectified voltages $v_{\text {rect } 1}$ and $v_{\text {rect } 2}$ at full load $\left[v_{a b}-v_{d f}: 500 \mathrm{~V} / \mathrm{div}\right.$; $v_{\text {rect } 1}, v_{\text {rect } 2} 100 \mathrm{~V} / \mathrm{div}$; time $\left.2 \mu \mathrm{s} / \mathrm{div}\right]$.

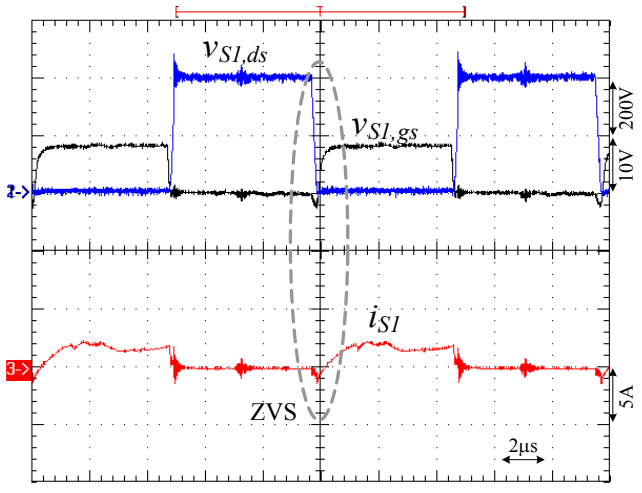

(a)

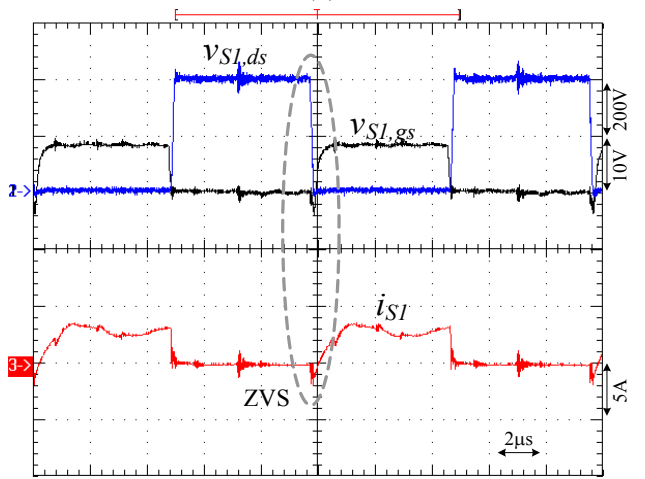

(b)

Fig. 10. Measured waveforms of gate voltage, drain voltage and switch current of $S_{1}$ at (a) $50 \%$ load and (b) full load.

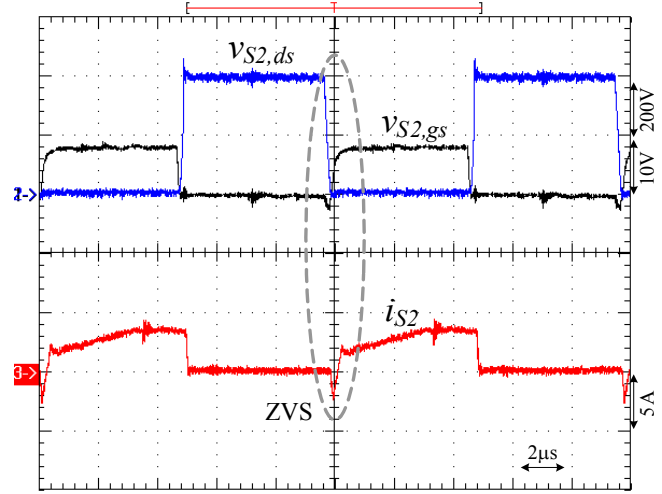

(a)

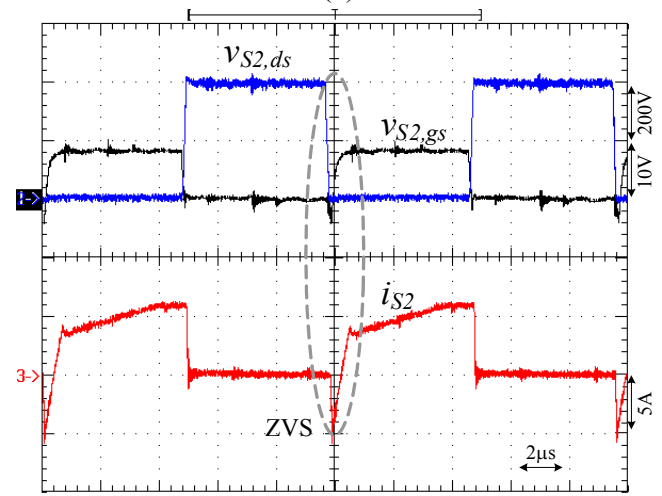

(b)

Fig. 11. Measured waveforms of gate voltage, drain voltage, and switch current of $S_{2}$ at (a) $50 \%$ load and (b) full load. 


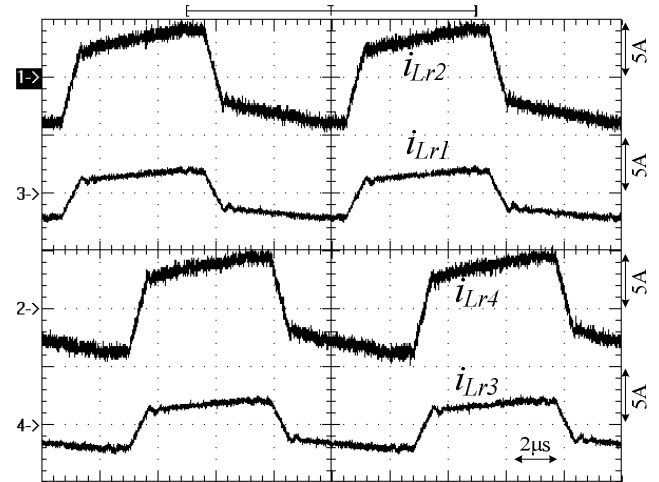

Fig. 12. Measured waveforms of inductor currents $i_{L r 1}-i_{L r 4}$ at full load.

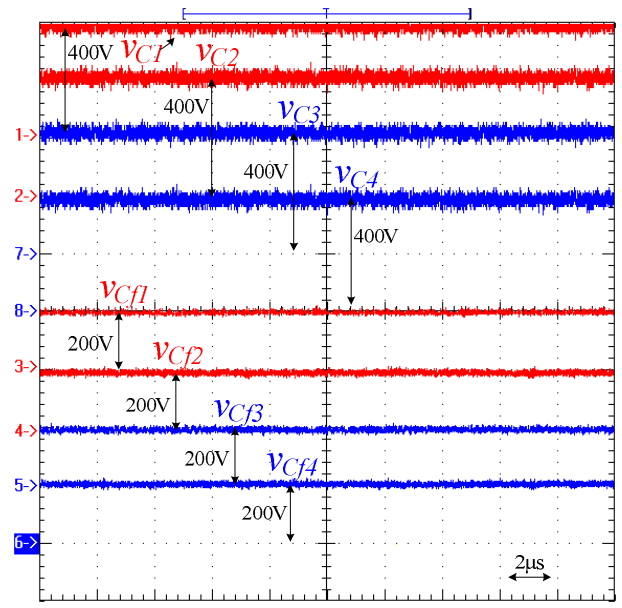

Fig. 13. Measured input capacitor voltages $v_{C I}-v_{C 4}$ and flying capacitor voltages $v_{C f I}-v_{C f 4}$ at full load.

under ZVS from $50 \%$ load to full load. Switches $S_{5}-S_{8}$ in the second circuit cell have the same PWM signals as $S_{1}-S_{4}$ in the first circuit cell. Thus, $S_{5}-S_{8}$ are also turned on under ZVS from $50 \%$ to $100 \%$ load. Fig. 12 shows the measured waveforms of inductor currents $i_{L r I}-i_{L r 4}$ at full load. When $v_{a b}$ is positive, inductor currents $i_{L r 1}$ and $i_{L 2}$ both increase. Moreover, inductor currents $i_{L r l}$ and $i_{L 2}$ both decrease when $v_{a b}$ is negative. Inductor currents $i_{L r 3}$ and $i_{L r 4}$ are phase-shifted by one-fourth of the switching period with respect to $i_{L r l}$ and $i_{L r 2}$. Fig. 13 shows the measured input capacitor voltages $v_{C I}-v_{C 4}$ and the flying capacitor voltages $v_{C f I}-v_{C f 4}$ at full load, and $V_{i n}=800 \mathrm{~V}$. The average flying capacitor voltages $v_{C f 1}-v_{C f 4}$ are equal to $200 \mathrm{~V}$, and the average voltages $v_{C l}-v_{C 4}$ are equal to $400 \mathrm{~V}$. The measured diode currents $i_{D I}-i_{D 4}$ at full load are shown in Fig. 14. Fig. 15(a) shows the output inductor current at full load without interleaved PWM operation. The measured ripple current is approximately $16 \mathrm{~A}$. Fig. 15(b) shows the measured output inductor currents $i_{L o l}$, $i_{L o 2}$ and the resultant output current $i_{L o 1}+i_{L o 2}$ at full load. Two output inductor currents $i_{L o 1}$ and $i_{L o 2}$ are balanced and phase-shifted by one-half of the switching period. The ripple current on $i_{L o 1}+i_{L o 2}$ is approximately $6 \mathrm{~A}$ in Fig. 15(b). From

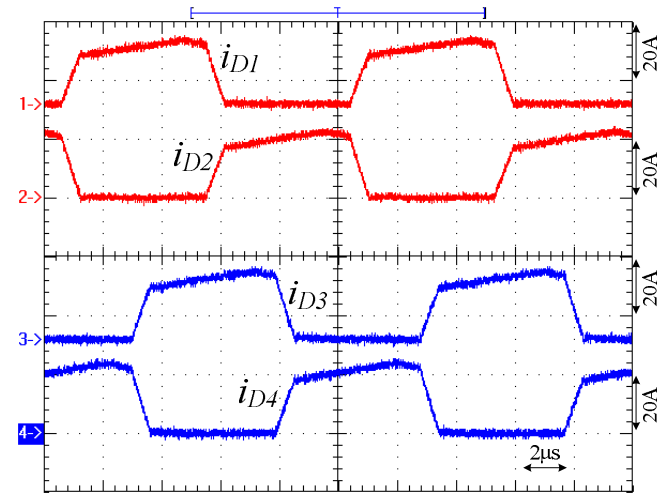

Fig. 14. Measured diode currents $i_{D I}-i_{D 4}$ at full load.

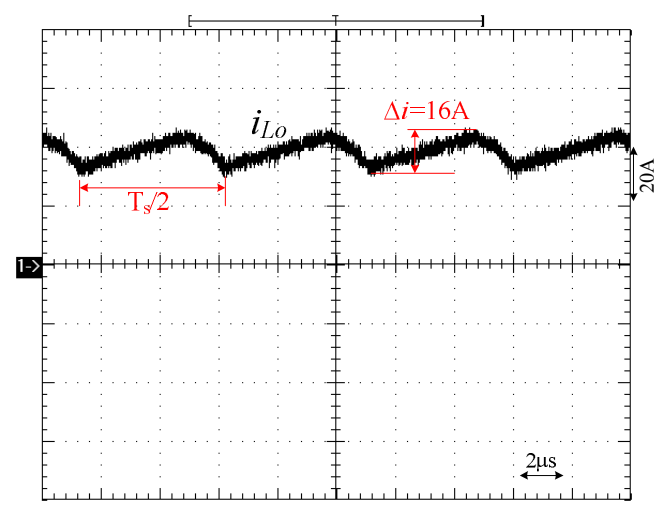

(a)

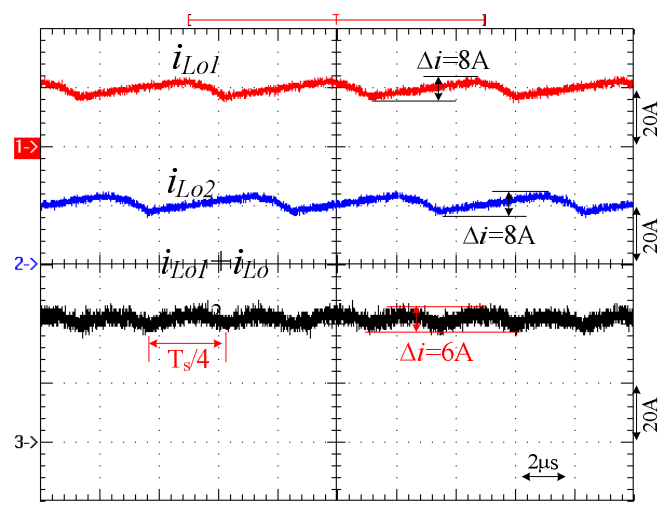

(b)

Fig. 15. Measured waveforms of output inductor currents at full load (a) without interleaved operation and (b) with interleaved operation.

Fig. 15, the resultant output inductor current iLo1+iLo2 with interleaved operation has less current ripple than the output inductor current without interleaved operation. Fig. 16 presents the measured output ripple voltage with and without interleaved PWM operation under full load condition. The proposed converter with interleaved PWM operation has low output ripple voltage. The measured circuit efficiencies at different input voltage and load conditions are shown in Fig. 17. 


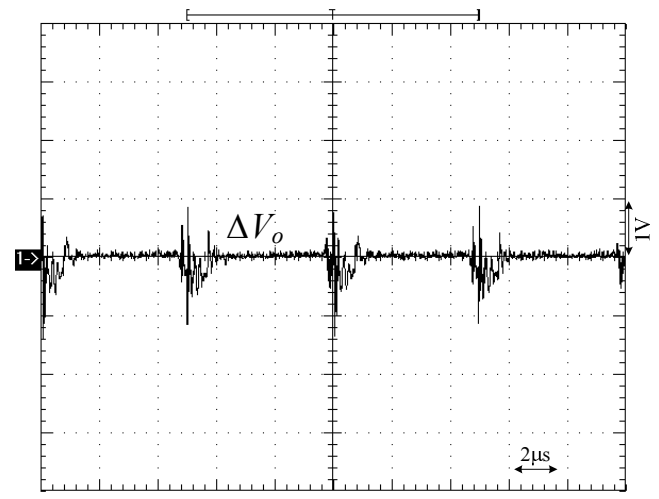

(a)

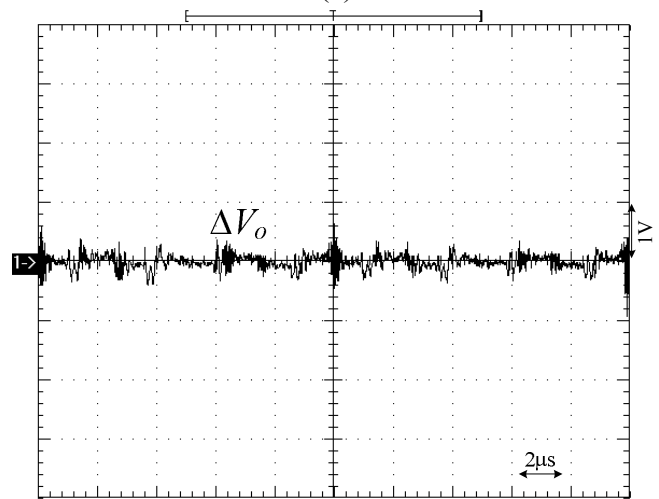

(b)

Fig. 16. Measured output ripple voltage under full load (a) without interleaved operation and (b) with interleaved operation.

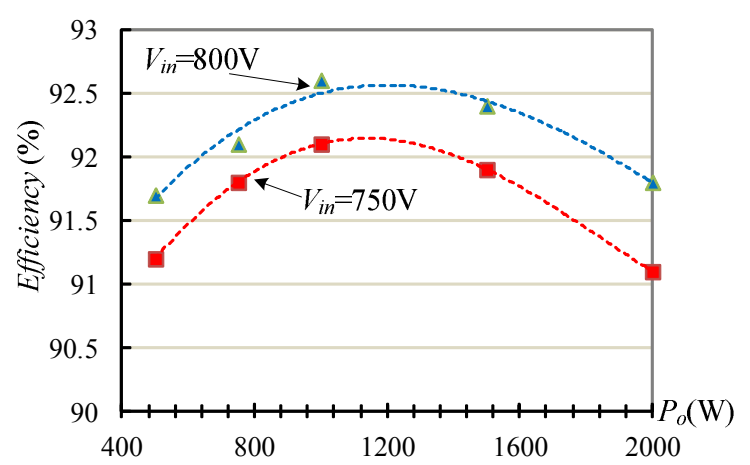

Fig. 17. Measured circuit efficiencies at different input voltage and load conditions.

\section{CONCLUSIONS}

A new three-level ZVS converter for high-input-voltage applications is presented with the features of ZVS turn-on for all switches from $50 \%$ load to full load, low voltage stress of power switches, and low voltage variation on output inductors. Two three-level converters are operated by interleaved PWM scheme to reduce the current rating of active and passive components and decrease the current ripple at the output side. In each converter, the voltage stress of power switches is clamped at $V_{i n} / 2$ by using three-level diode clamped topology. Two flying capacitors are adopted in each circuit cell to balance two input split capacitor voltages. The proposed three-level converter combines one half-bridge PWM converter and one three-level PWM converter to reduce the output inductor voltage variation. Therefore, the switching current in the output capacitor can be reduced compared with the switching capacitor current in the conventional three-level PWM converter. Finally, experiments are provided to verify the effectiveness of the proposed converter.

\section{ACKNOWLEDGMENT}

This project is partly supported by the National Science Council of Taiwan under Grant NSC 102-2221-E-224-022-MY3.

\section{REFERENCES}

[1] H. Akagi and R. Kitada, "Control and design of a modular multilevel cascade BTB system using bidirectional isolated DC/DC converters," IEEE Trans. Power Electron., Vol. 26, No. 9, pp. 2457-2464, Sep. 2011.

[2] J. Rodriguez, J.-S. Lai, and F. Z. Peng, "Multilevel inverters: a survey of topologies, controls, and applications," IEEE Trans. Ind. Electron., Vol. 49, No. 4, pp. 724-738, Aug. 2002.

[3] M. Malinowski, K. Gopakumar, J. Rodriguez, and M. A. Pérez, "A survey on cascaded multilevel inverters," IEEE Trans. Ind. Electron., Vol. 57, No. 7, pp. 2197-2206, Jul. 2010.

[4] A. Nami, F. Zare, A. Ghosh, and F. Blaabjerg, "A hybrid cascade converter topology with series-connected symmetrical and asymmetrical diode-clamped H-bridge cells," IEEE Trans. Power Electron., Vol. 26, No. 1, pp. 51-65, Jan. 2011.

[5] F. Canales, P. M. Barbosa, and F. C. Lee, "A zero-voltage and zero current-switching three level DC/DC converter," IEEE Trans. Power Electron., Vol. 17, No. 6, pp. 898-904, Nov. 2002.

[6] J. P. Rodrigues, S. A. Mussa, I. Barbi, and A. J. Perin, "Three-level zero-voltage switching pulse-width modulation DC-DC boost converter with active clamping," IET Power Electron., Vol. 3, No. 3, pp. 345-354, May 2010.

[7] B.-R. Lin, S.-K. Chung, and T.-Y. Shiau, "Zero-voltage-switching DC/DC converter with three three-level pulse-width modulation circuit cells," IET Power Electron., Vol. 6, No. 1, pp. 1-8, Jan. 2013.

[8] Y. Firouz, M. T. Bina, and B. Eskandari, "Efficiency of three-level neutral-point clamped converters: analysis and experimental validation of power losses, thermal modelling and lifetime prediction," IET Power Electron., Vol. 7, No. 1, pp. 209-219, Jan. 2014.

[9] Y. Shi and X. Yang, "Wide range soft switching PWM three-level DC-DC converters suitable for industrial applications," IEEE Trans. Power Electron., Vol. 29, No. 2, pp. 603-616, Feb. 2014.

[10] B.-R. Lin and C.-C. Chen, "New three-level PWM DC/DC Converter - analysis, design and experiments," Journal of Power Electronics, Vol. 14, No. 1, pp. 30-39, Jan. 2014.

[11] R. Cheng, Y. Yang, H. Liang, and Y. Jiang, "Thin-film integrated magnetic component for three-level LLC resonant converter," in Proc. IEEE ICIT Conf., pp. 739-743, 2005. 
[12] Y. Gu, Z. Lu, L. Hang, Z. Qian, and G. Huang, "Three-level LLC series resonant DC/DC converter," IEEE Trans. Power Electron., Vol. 20, No. 4, pp. 781-789, Jul. 2005.

[13] W. Chen, Y. Gu, and Z. Lu, "A novel three level full bridge resonant DC-DC converter suitable for high power wide range input applications," in Proc. IEEE-APEC Conf., pp. 373-379, 2007.

[14] B.-R. Lin and P.-J. Cheng, "Analysis of an interleaved zero-voltage switching/zero current switching resonant converter with duty cycle control," IET Power Electron., Vol. 6, No. 2, pp. 374-382, Feb. 2013.

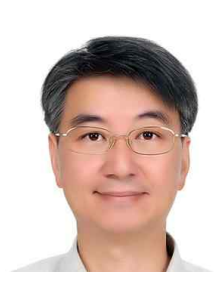

Bor-Ren Lin received his B.S.E.E. degree in Electronic Engineering from the National Taiwan University of Science and Technology, Taipei, Taiwan, in 1988 and his M.S. and Ph.D. degrees in Electrical Engineering from the University of Missouri-Columbia, USA, in 1990 and 1993, respectively. From 1991 to 1993, he was a Research Assistant with the Power Electronic Research Center, University of Missouri. Since 1993, he has been with the Department of Electrical Engineering, National Yunlin University of Science and Technology, Douliou, Taiwan, where he is currently a Distinguished Professor. He is an Associate Editor of the Institution of Engineering and Technology Proceedings-Power Electronics and the Journal of Power Electronics. His main research interests include power-factor correction, multilevel converters, active power filters, and soft-switching converters. He has authored more than 200 published technical journal papers in the area of power electronics. Dr. Lin is an Associate Editor of the IEEE Transactions on Industrial Electronics. He was the recipient of Research Excellence Awards in 2004, 2005, 2007, and 2011 from the Engineering College and the National Yunlin University of Science and Technology. He received the Best Paper Awards from the 2007 and 2011 IEEE Conference on Industrial Electronics and Applications, Taiwan Power Electronics 2007 Conference, and the IEEE-Power Electronics and Drive Systems 2009 Conference.

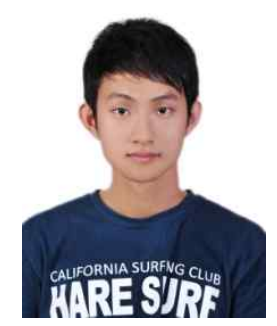

Yu-Bin Nian is currently working toward his M.S. in Electrical Engineering from the National Yunlin University of Science and Technology, Yunlin, Taiwan, ROC. His research interests include the design and analysis of power-factor correction techniques, switching-mode power supplies, and soft-switching converters. 